dows, bells were run ? violently; windows were thrown tip, and cries of 'Thieves' and 'Police' were shouted. But the re was no earthquake, there were no thieves. although there were the poilice, by whom the sounds were dis inctly heard. It was some time before all was again quiet, and not even then in many a househo!d until proces ions in curious ga,b, armed with sticks, pokers, shovels, and fire-irons, in place of fire-arms, had parad d from kitchen to garret in search of the supposed nocturnal marauders. And now the cause of all this has been di-covered. It was the coastgu urd squadron, a few miles out at sea, having what is termed their night quarter exercise-a turn-out drill in the mirdle of the night, so as to fit the men for action in an emergency."

Chuch Hill, Brighton, September II

E. A. PANKHUKST

\section{A Fossiliferous Boulder}

DURING a visit I made in July last to a respected friend at Dinnington, Northumberland, I observed a travelled $b$ nlder in the corner of his field, and, on closer inspection, found that it contrined a number of ammonites, encrinites, and the detached portions of the :trms of the stone lily, usually found in the Lias in the vicinity of Whitby. The composition of the boulder, which was ab.ut two fret in length, and of proportionate breadth and depth, was basaltic or trap, and had rvidently taken up the fossils when in a state of fusion; some of the ammonites being compressed or disturbed. Upon inquiry, it appeartd that my frien had su. $k$ for a well, and came at the depth of about twe? ve feet upon the native freestone rock, upon which this houlder wa. found. Of course it must have bren transported to its place of deposit by ice during the glacial period of our world's history, and then covered over by the subsequent boulder-clay; but from whence was it transported? From Yorkshire or the Hebrides?

$I$ also visited in the immediate vicinity what was formerly the site of an ancient lake of about $\mathrm{I}, 200$ acres, Prestwick Car. This sheet of wa er was drained a few years ago into the Pont rivulet, and the bed of the old lake iv now, through the enterprise and skilful industry of the farmer, covered by luxuriant crops of oa $\mathrm{s}$ with magnificent heads, approaching six feet in height, and immense thickness of stem. The land, as might be extected, is a derp hog earth; the surface, however, is remarkably light, apparently a leaf soil, and easily disturbed, or hown awav by the winds. The remarkable point here was, that after the drainage had been completed, the earth soldified and put under culture, the roos and a porrion of the stems of trees broken off near the roots, appeared as if rising from the earth, the prior existence of which was uneen and unkniwn, indicating the remains of a primæval forest : no hranches appeared. The wood is that of the alder. Was not the lake ori inally formed by the destruction of this ancirnt forest by the agency of wind?

Barbourne, Worcester, Sept. 9

J. Brough Pow

\section{A Vital Question}

PKAY do not mind if $I$ am alone in my venturesomeness, but in the name of Science, not that which is falsely so cailed, but that which depends upin evidence, let me prutest against the doctrne contained in the concluding portion of Sir W. Thomson's address. Scholastic theology has for me nothing wors: than the declaratiun, made on the strength of a mere dogma, that our dear mother earth is no mother at all, but absolutely in apible of filing any function in the production of her own c iildren. The dugme that life can only proced from life, a pears, when anılıs d, like too many another dognia, but a meaningless jingle of words.

Here are three counter-propositions, which I advance in all confidence of their soundness :-

1. We know nuthing whatever of the nature of life to justify us in asserting its absolute difference in kind from many uther phenomena, as of magnetism, chemistry, or Nature in general.

2. If, as as ronomers hrold, all the bodies composing the solar system are derived from the sum, they must contain itlentical elements. That their elements are actually ident cal is, moreover, indicated thy the spec roscope so that if tho e elements be incapable of protucing life on this planer, they mu $t$ be incarrable of producinv itelsewhe e. However much re son there may be to suppo e they have $n$ it produc d lif in any particula instance as yet, as, e.g., in our satellite, that is no reason against their doing so in the future. If Sir William's object had been to gain time for existing evolutions, I could have forgiven him, but there was no hint of this.

3. To speak of life as necessary to the production of life, is to ignore all that Science has ascertained respecting the transference and convertibility of force, and to fill back unon the arthro. pomorphi-m of the theologians, only with the difference, in this case, that it is not Jupiter, but "the stone that fell down from Jupiter," whom we are to hail as our father and mother. Moreover, to speak of life as necessary to the production of life, is to as itume that we already know the limits of Nature's productive power; and to assert that life is not a natural product at a!I, is to restrict our definition of Nature by some arbitrary limit which exc udes the most imnortant functions of Nature.

Doubtless it would be a very pretty idea to regard the planets as so many orchids in the flower-garden of the Universe, and the meteorites as their fertilising bees; but Sir W. Thomson entertains no such pleaing sentiment respecting the earth. He drgrades this unhappy panet far below the meteorite.

Once upon a time witen astray with a companion in a far Western wilderness, we were reduced to eating anything that we cou $d$ find. On the question arising whether rat.lesnates were fit to eat, I propounded the dictum that whatever could itself live ought to be able to support lite in another, and our experience, so far as it went confirmed the saying. I venture to vary it for Sir W. Thomson's benefi, and to suggest that whate ver can support life, as this earth does, can in all probability produce it. Loving, as I do, bo h the world and the thines which are in the world, I hope you will not refuse me a comer for this sorrow. ing dissent from a doctrine so depre iatory of the world, and whose enunciation cannot fail to give occasion to the many enemies of Science to bla pheme its sacred name on account of the eccentricities of its professors.

Oxford and Cambridge Club

\section{Draining a Cause of Excessive Droughts}

WILL you kindly allow me through the medium of NATURE to ask whether any of my feilow readers can give me any actually observed facts, to show that draining is justly considere t an item in the suon of causes which have given rise to the lengthesed periods of drought that we have experienced in these islands for the last few years. As a matter or reasoning I believe it is generally admitted that such is the case, for ampie evidence his been produced by actual experiment to show that draining raises the temperature of the land and the air above it; and if so, it would le.sen the chance of the vap ur suspended in the atmosphere being condensed. Such observed facts are on recurd as regards the cutting of forests, $e g$, N+TURE, vul. iv. p. $5 \mathrm{r}$, "Buchan's Meteurolugy," $\mathrm{p} .88$, and if my memory dues not fa: me, some information was given on both these points in a previous volume of NATURE, bui I am at present unable to lay my hands upon it, though I have glanced over the pages as well as the index.

If any one will kindly furnish me with the information, which may also be of interest to others, or refer me to a work not difficult of access, I shall be extremely obliged.

Thomas FaWcetT

\section{Rainbow}

$\cap_{N}$ Friday, the 8th July, about four P.M., as I W's driving acro s the Boy of Allen, aiout eight niles frum Edenderry, I wberved the must briliant raiubuw I have tver beheld einer in Eurepe or India. It aipeared in the Norch, and was low down on the flat horizon, being an $\operatorname{arc}$ of $60^{\circ}$ with the horizon as its chord. The ends of the bow were nearly due $E$. and $W$. The spectrum was intensely vivid. A second bow, imperfect towards the centre, shortly afterwards appeared above it; in perhaps five minutes, the $\mathbb{E}$. end of this upper bow faded, and immediately I perceived for a corresponding length of the true rainbow, bordering the violet, a well defined rim of sta green, this bounted by a band of almost mauve-coluured vivlei, which shaded off in o the in tigo sky.

The under-side of the oppoite end of the bow (above which the purtinn of the upjer bow was strli visibie, preen ed no such appearance.

Next day I learnt that, about the same hour, a thunderstorm 